\title{
IMPLEMENTATION OF MOMENT INVARIANT IN RECOGNIZING OF ELECTRICAL METER NUMBERS
}

\author{
Lukman Syafie ${ }^{1}$, Herman $^{2}$, Nur Alam ${ }^{3}$, Tasmil $^{4}$ \\ ${ }^{12}$ Computer Science Dept. Universitas Muslim Indonesiaut, Indonesia \\ ${ }^{34}$ Balai Besar Penelitian dan Pengembangan SDM KOMINFO Makassar, Indonesia \\ 1'lukman.syafie@umi.ac.id, ${ }^{2}$ herman@umi.ac.id, ${ }^{3}$ nura012@kominfo.go.id, ${ }^{4}$ tasmil@kominfo.go.id
}

\begin{abstract}
Implementation of computer vision can be done in the introduction of images or pictures of characters of numbers or letters. Based on this, then the computer vision can be used in the introduction of numbers on the electric meter or commonly called $\mathrm{kWh}$ meter. The underlying thing for the electric meter to be the object of research is to look at the situation, where the electric meter recorder keeps the record using the camera. Furthermore, the value shown on the electric meter will be inputted manually. Manual input requires a relatively long time because the amount of electricity meter input value is not small data. One method that can be used in recognizing the shape of the image in computer vision is the invariant moment. The results of this study indicate that the quality of the image gives effect, both in terms of the extraction of features and the accuracy of the recognition of the figure on the image of the electric meter. In addition to this, the threshold value of the euclidian distance method should also be used to limit the recognition process.
\end{abstract}

Keywords: electric meter image; computer vision; moment invariant.

\section{INTRODUCTION}

Computer vision is a discipline with the aim of making the system automatically recognize objects based on images or videos [1]. The application of computer vision can be done in recognize the character images of numbers or letters. At present, a lot of research on the recognize of letter or number patterns using computer vision. Based on this, computer vision can be used in recognize numbers on the electricity meter or what is commonly called the $\mathrm{kWh}$ meter. The thing that underlies the electric meter to be the object of research is to see the situation that occurs, where the electric meter registrar records using a camera. Furthermore, the value indicated on the electric meter will be input manually. Inputting manually requires a relatively long time because the amount of electricity meter inputted is not small. According to Azhar et.al [1], that computer vision systems can help humans in some jobs.

Some researchers have conducted research related to computer vision in the recognize of letters and numbers, including Vaishnav and Mandot [2]. In that study, the template matching method was used to introduce number plates. The same method is also used by Choudhury and Negi [3] and Mayan et.al [4] to conduct research related to the introduction of vehicle plate numbers. Template matching is one of the methods related to computer vision that is used for identification or identification. Jayasekara and Kumara [5], resulted in an accuracy rate of $90.96 \%$ in character recognition numbers and $63.69 \%$ for letters. Then Kalina and Golovanov [6] used template matching in numeric recognition.

All research that has been discussed uses template matching and results in a fairly high degree of recognition accuracy. However, according to researchers, template matching is not suitable for use when the distance of shooting or the distance between the object and the camera and the angle of shooting is not fixed. In [4], it states that the pattern matching template matching is based on the pixel values in the image or image. If the distance of the object and the camera is uncertain, it means that the resulting image will have a different size of the object even though the size of the image or image is the same.

In conducting the recognize of electric meter numbers, researchers focus on the shape of the numbers because the shape of the numeric characters for each electric meter is almost the same. On this basis, the researcher proposes to use the moment invariant feature extraction method. Invariant moments can describe an object without depending on position and size [7].

\section{MethodE}

The design of the system of this study consists of 2 parts, namely data collection and data processing. Data collection is the process of collecting data that will be used as a knowledge base in the process of recognize. The recognition process is the process of getting information about the numbers contained in the electric meter image or image. However, before carrying out the data collection and introduction process, it must first take an image of an electric meter or in computer science terms known as image acquisition. The description of the system design, shown in Figure 1.

In Figure 1, it can be seen that the data collection process and the recognize process are preceded by the process of image acquisition of electric meter. In the process of image acquisition, the tool used is a cellphone camera officers. 


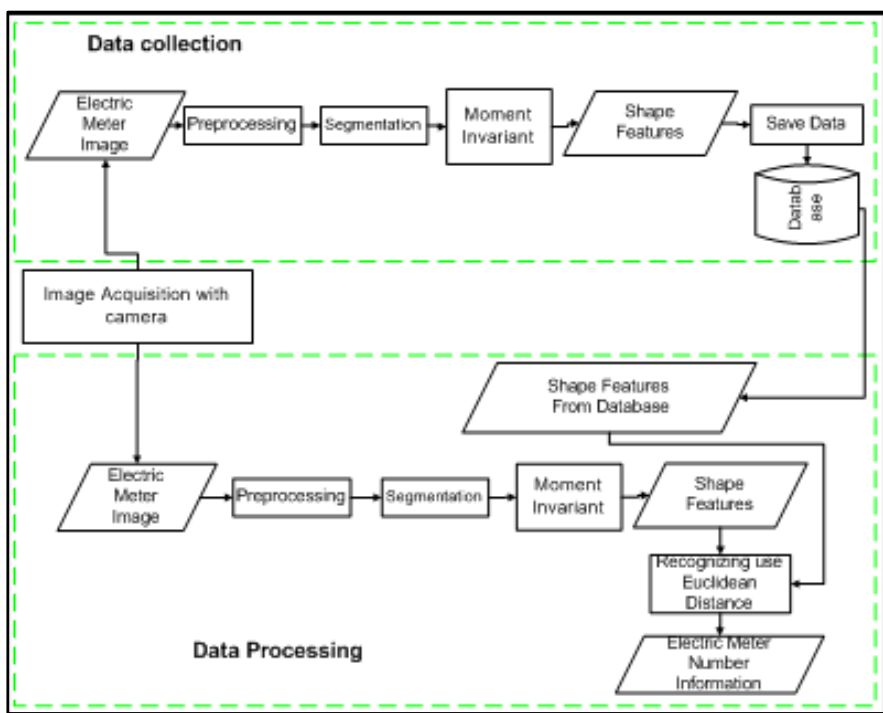

Fig. 1. System design

Next converted images. Then the image that has been through pre-processing, then cropped to retrieve the numeric area of the electric meter image. The next step is segmentation to separate the numeric objects from the background by converting the image from gray level to black and white image and proceed to separate each number from the converted image. Then the segmented image is extracted using the invariant moment and produces 7 feature values. An overview of data processing can be seen in Figure 2.

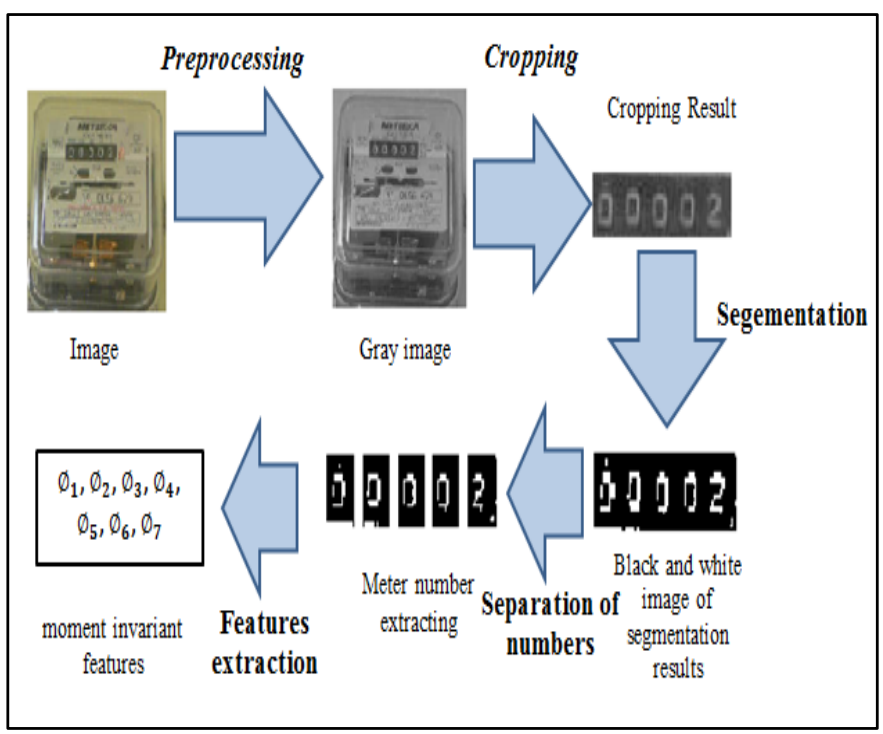

Fig. 2. Data processing

The moment invariant feature data that is generated from the feature extraction process will be compared with the characteristic data numbers from 0 to 9 that have previously been stored in the database. The method used in comparing data is euclidian distance. The equation used to get the moment invariant feature, shown in equation (1) and for euclidian distance, is shown in equation (2).

$$
\begin{aligned}
& \emptyset_{1}=\eta_{20}+\eta_{02} \\
& \emptyset_{2}=\left(\eta_{20}-\eta_{02}\right)^{2}+\left(2 \eta_{11}\right)^{2} \\
& \emptyset_{3}=\left(\eta_{30}-3 \eta_{12}\right)^{2}+\left(\eta_{03}-3 \eta_{21}\right)^{2} \\
& \emptyset_{4}=\left(\eta_{30}+\eta_{12}\right)^{2}+\left(\eta_{03}+\eta_{21}\right)^{2} \\
& \emptyset_{5}=\left(\eta_{30}-3 \eta_{12}\right)\left(\eta_{30}+\eta_{12}\right)\left[\left(\eta_{30}+\eta_{12}\right)^{2}-3\left(\eta_{21}+\eta_{03}\right)^{2}\right]+ \\
& \quad\left(\eta_{03}-3 \eta_{12}\right)\left(\eta_{03} \eta_{21}\right)\left[3\left(\eta_{12}+\eta_{30}\right)^{2}-\left(\eta_{03}+\eta_{12}\right)^{2}\right] \\
& \emptyset_{6}=\left(\eta_{20}-\eta_{02}\right)\left[\left(\eta_{30}+\eta_{12}\right)^{2}-\left(\eta_{21}+\eta_{03}\right)^{2}\right]+ \\
& \quad 4 \eta_{11}\left(\eta_{30}+\eta_{12}\right)\left(\eta_{03}+\eta_{21}\right) \\
& \emptyset_{7}=\left(3 \eta_{21}-\eta_{03}\right)\left(\eta_{30}+\eta_{12}\right)\left[\left(\eta_{30}+\eta_{12}\right)^{2}-3\left(\eta_{21}+\eta_{03}\right)^{2}\right]+ \\
& \left(3 \eta_{12}-\eta_{30}\right)\left(\eta_{03}+\quad \eta_{21}\right)\left(3\left(\eta_{30}+\eta_{12}\right)^{2}-\left(\eta_{03}+\eta_{21}\right)^{2}\right)(1) \\
& d(x, y)=\sqrt{\left(x_{1}-y_{1}\right)^{2}+\left(x_{2}-y_{2}\right)^{2}+\left(x_{3}-y_{3}\right)^{2}+\cdots+\left(x_{n}-y_{n}\right)^{2}}
\end{aligned}
$$

\section{RESULT AND DISCUSSION}

Testing the recognition of electric meter image numbers is done with 2 approaches. The approach in question is the testing of the feature extraction using moment invariant and the second is the testing of the ability of the application to perform the introduction of electric meter image numbers.

The first test is done using images that have good lighting quality and shooting position. In Figure 3 displays the results of the moment invariant feature extraction.

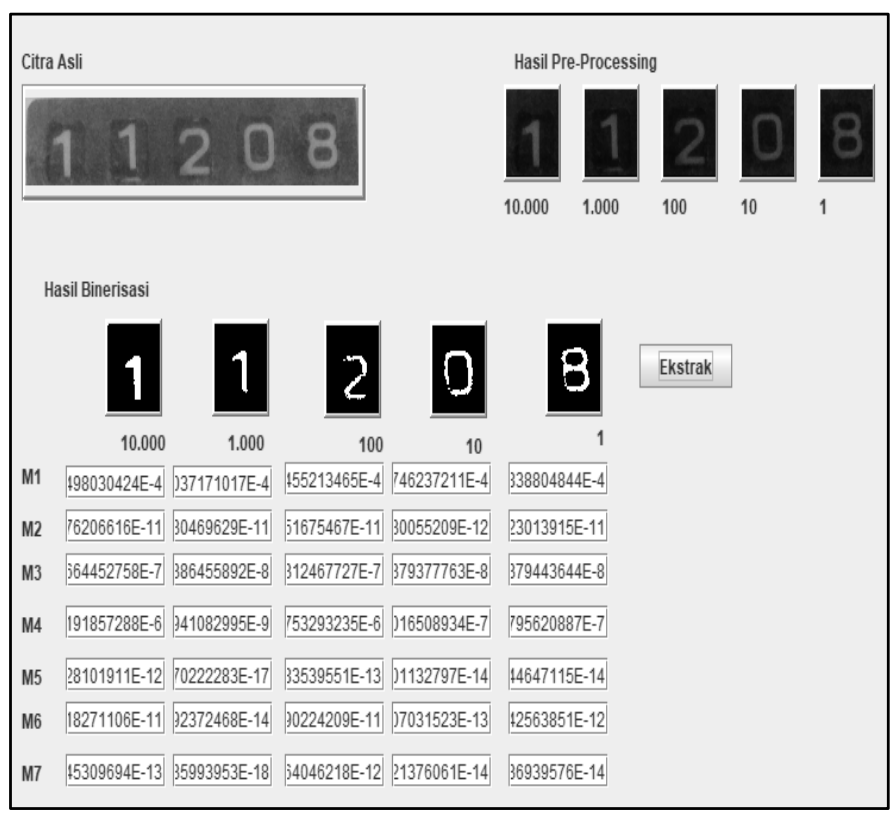

Fig. 3. Feature extraction of invariant moments

In Figure 3, the application is able to get the invariant moment characteristic of the electric meter image. This happens because the figures resulting from binarization are clearly visible numbers. Furthermore, testing is done on images that have low quality. Figure 4 shows the next feature extraction test. 


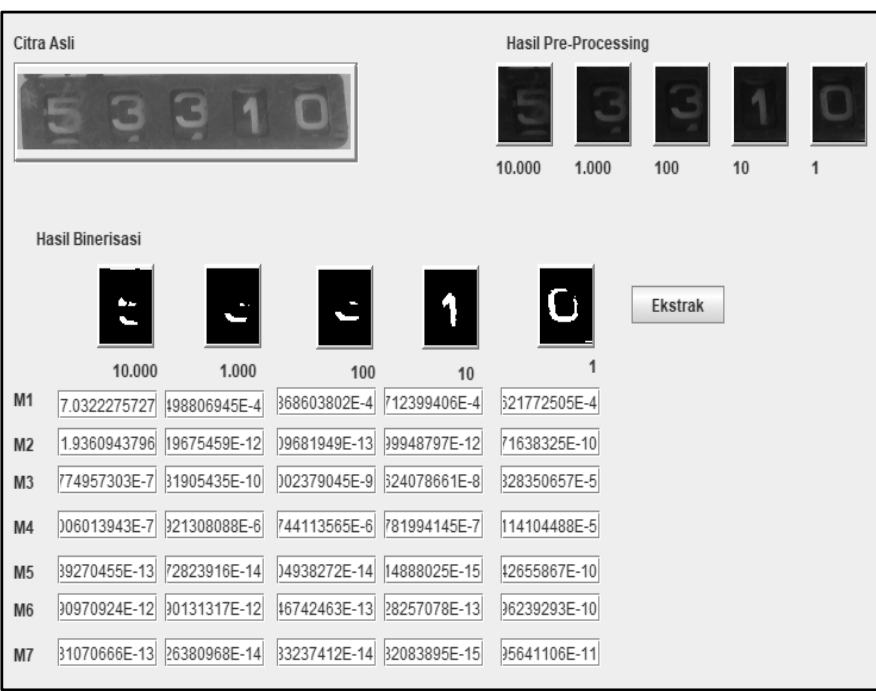

Fig. 4. Feature extraction of invariant moments with low quality images

In Figure 4, the application is still able to get the moment invariant feature, but the resulting binary image does not perfectly display the actual numeric form. This happens because the quality of the gray image conversion results (grayscale) is not very clear displaying numbers. Next, it is tested again using lower image quality. Figure 5 displays the test results using a lower image quality compared to previous tests.

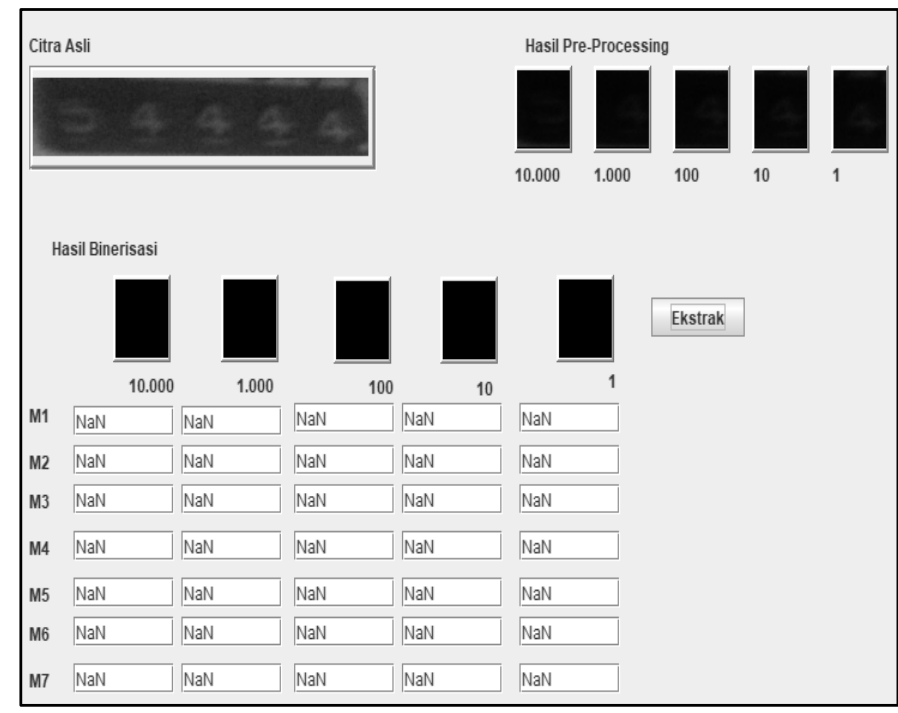

Fig. 5. Feature extraction with blurry image quality

In Figure 5, the application cannot display feature extraction. This is due to blurred image quality. The number of figures in the original image is not very clear and tends to approach the background color of the image. This results in the conversion of gray images and binary results do not produce numeric images and cause can not produce the desired characteristics.

Based on the results of the moment invariant feature extraction test, image quality has an influence in producing numerical features from the electric meter image. Images that are blurry and have poor lighting will be difficult to extract the figure features compared to images that have good lighting.

Next is testing the recognize of electric meter image numbers. This test aims to measure the application's ability to perform numeric recognition on the inputted electricity meter images. Figure 6 shows the results of number recognition.

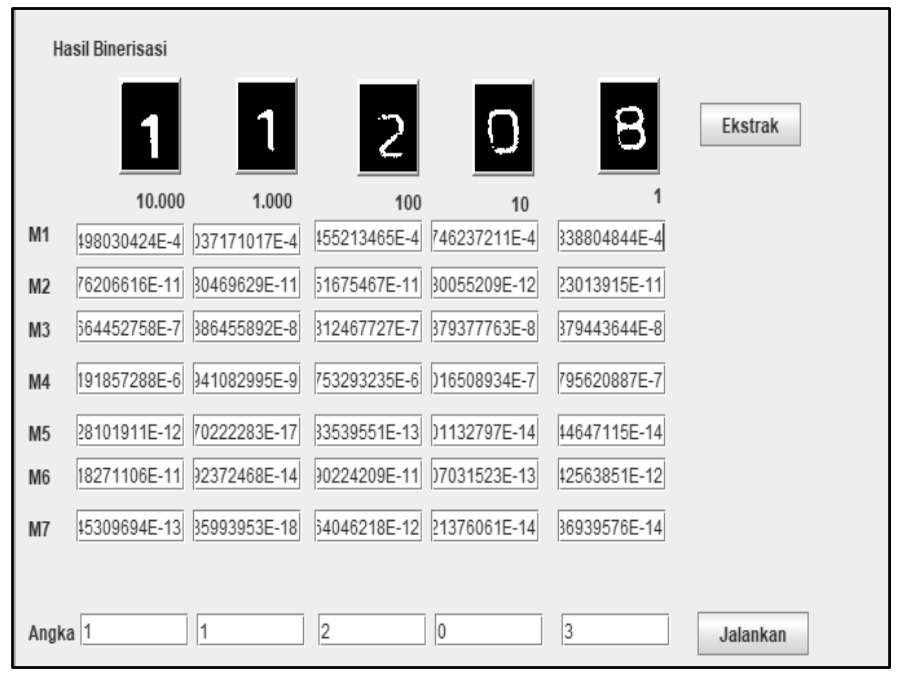

Fig. 6. The results of the recognition of electric meter images

In Figure 6, the number 8 is recognized as number 3. This occurs because the shape of the number 8 in the binaryization has the form approaching the number 3 . On the left side of the number 8 has a thin line and this affects the reading of the number. Then further tested using a blurred image quality. Figure 7 shows the intended test results.

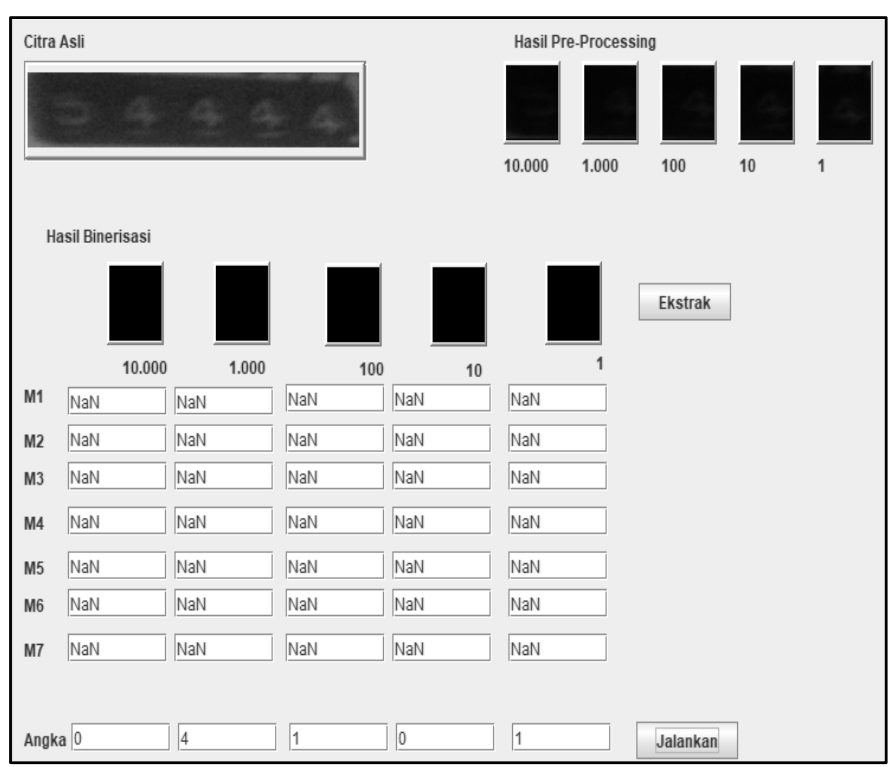

Fig. 7. The results of recognition with low image quality

In Figure 7, although it does not produce characteristic values, it can produce numerical recognition. The results of the introduction of numbers are very much different from the 
original image. This happens because the recognition method used is euclidian distance which does not use a threshold value. So when the application does an introduction based on the knowledge base stored in the database, the first data in the database is displayed. In addition to image quality, the threshold value in the euclidian distance method also has an influence in the number recognition process in the electric meter image.

\section{CONCLUSION}

From the results of this study, several conclusions were obtained, namely:

1. Image quality influences the feature extraction process using invariant moments.

2. In addition to image quality, the determination of the threshold value in the euclidean distance method also has an influence in the number recognition process in the electric meter image.

\section{ACKNOWLEDGMENT}

This research cannot be completed without help from other parties. therefore, the authors thank the Faculty of Computer Science for morally supporting and infrastructure. Acknowledgments also the author gave to the Universitas Muslim Indonesia for providing financial assistance so that this research can be implemented.

\section{REFERENCES}

[1] K. Azhar, F. Murtaza, M. H. Yousaf, and H. A. Habib, "Computer vision based detection and localization of potholes in asphalt pavement images," Can. Conf. Electr. Comput. Eng., vol. 2016-October, pp. 1-5, 2016.

[2] A. Vaishnav and M. Mandot, “An Integrated Automatic Number Plate Recognition for Recognizing Multi Language Fonts," 2018 7th Int. Conf. Reliab. Infocom Technol. Optim. Trends Futur. Dir. ICRITO 2018, pp. 551-556, 2018.

[3] A. Choudhury and A. Negi, "A New Zone Based Algorithm for Detection of License Plate from Indian Vehicle," 2016.

[4] J. Albert Mayan, K. A. Deep, M. Kumar, L. Alvin, and S. P. Reddy, "Number plate recognition using template comparison for various fonts in MATLAB," 2016 IEEE Int. Conf. Comput. Intell. Comput. Res. ICCIC 2016, 2017.

[5] J. M. N. D. B. Jayasekara and W. G. C. W. Kumara, "Text extraction for Sri Lankan number plates," 2015 8th Int. Conf. Ubi-Media Comput. UMEDIA 2015 Conf. Proceeedings, no. c, pp. 89-91, 2015.

[6] D. Kalina and R. Golovanov, "Application of template matching for optical character recognition," Proc. 2019 IEEE Conf. Russ. Young Res. Electr. Electron. Eng. ElConRus 2019, pp. 2213-2217, 2019.

[7] . H. and A. Harjoko, "Pengenalan Spesies Gulma Berdasarkan Bentuk dan Tekstur Daun Menggunakan
Jaringan Syaraf Tiruan," IJCCS (Indonesian J. Comput. Cybern. Syst., vol. 9, no. 2, p. 207, 2015. 